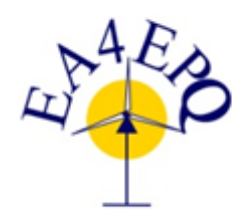

$19^{\text {th }}$ International Conference on Renewable Energies and Power Quality (ICREPQ'21)

Almeria (Spain), $28^{\text {th }}$ to $30^{\text {th }}$ July 2021

Renewable Energy and Prever Quality Frumal (RE\&PQJ)

ISSN 2172-038 X, Volume No.19, September 2021

\title{
Techno-Economic Assessment of Concentrated Solar and Photovoltaic Power Plants in Brazil
}

\author{
Guilherme de Sousa Torres*, Tulio Andre Pereira de Oliveira*, Anesio de Leles Ferreira Filho*, \\ Fernando Cardoso Melo *, Elder Geraldo Domingues ${ }^{\dagger}$ \\ *Department of Electrical Engineering \\ University of Brasilia \\ e-mail: gstorres.ene@gmail.com,tulio.apo612@gmail.com,leles@ene.unb.br,fernando.melo@ene.unb.br \\ ${ }^{\dagger}$ Engineering College \\ Federal Institute of Goias \\ e-mail: prof.eldergd@gmail.com
}

\begin{abstract}
The need for a diverse energy matrix has been promoting a favorable environment for integrating new renewable energy sources, such as Concentrated Solar Power plants (CSPs). Nonetheless, as a consequence of the incipient solar generation via CSPs in Brazil, there is a unsatisfactory number of researches that handle technical and economic assessments of CSP plants performance on this country. Given this scenario, this study proposes an assessment of the technoeconomic viability of the implementation of 100 MW CSP plants in Brazil, considering the Solar Tower (ST) systems, Parabolic Trough Collectors (PTC), Linear Fresnel (LFR) Reflectors and Dish Stirling (DS) Systems, and comparing the results to a photovoltaic (PV) plant. This study utilizes project data of power plants collected from the relevant literature and applies it to the city of Bom Jesus da Lapa, Brazil. The CSP techno-economic viability is evaluated through the analysis of the annual energy generated, as well as the economic viability indicators, such as the Net Present Value, the Internal Rate of Return, the Discounted Payback and the Levelized Cost of Energy, and through a single-variable sensitivity analysis. This analysis employs the discounted cash flow model, considering the energy trade in a Regulated Contracting Environment.

Keywords-CSP, Renewable Energy, Economic Assessment, Solar Energy, Cash flow analysis, System Advisor Model, Photovoltaic Systems
\end{abstract}

\section{INTRODUCTION}

A reliable electric system is required for meeting a country's energy demand and to expand its productive capacity. However, in order to achieve such goal, it is fundamental to rely on a diverse energy matrix capable of minimizing supply risks and diminishing energy expenditures. In this sense, some countries have been seeking this diversification by integrating renewable energy sources to the power grid and creating a favorable economic environment for them [1]-[3].

In this context, it is worth mentioning those regions that compose the so called Solar Belt, like China, India, Latin America, the Mediterran and Northern Africa, where the high values for Direct Normal Irradiance (DNI) and Global Horizontal Irradiance (GHI) favor the integration of solar-based sources, such as photovoltaic systems, and concentrated solar power (CSP) topologies [4]. The literature has been pointing out both technical and economic viability of these sources in a variety of places, especially for photovoltaic projects which technological advances, associated with government incentives, have been consolidating these systems as one of the most viable solar sources.

Brazil is among these countries that have made an effort to diversify their matrix by decreasing the dependence on hydropower systems and incorporating technologies like photovoltaics, wind and biomass. The Normative Resolution 482/2012 from National Electric Energy Agency (ANEEL), focused on regulating the mini and micro Distributed Generation (DG) systems, is the landmark of this effort and was responsible for mass integration of photovoltaic systems, which reduced the implementation costs and became a more attractive investment [5].

However, despite its benefits, photovoltaic solar generation encounters a strong barrier when it comes down to applications of this technology in large-scale plants, mainly due to the intermittent nature of solar irradiation and the high costs of storage systems. In this sense, CSP topologies are getting more interesting [6]. Although it is also dependent on solar radiation availability for energy generation, the use of molten salt as a storage fluid increases the power plant capacity factor without high implementation costs as a counterpart.

Concomitantly, it is observed in the literature an incipient number of studies dedicated to building an in-depth research, considering a larger set of viability indicators, besides the Levelized Cost of Energy (LCOE) [7], [8]. Furthermore, a lack of studies comparing the performance of photovoltaic systems and CSP topologies under the same circumstances is also observed.

Based on these facts, this paper proposes a technical and economic assessment for the four main CSP topologies, namely, 
ST, PTC, LFR and DS Systems, and also for a PV power plant. The outcomes for energy generation and viability indicators are then compared in order to assess the economic feasibility of each plant. A sensitivity analysis is also carried out to understand which variables impact the most on the economic viability, as well as to indicate possible measures to be taken by the government, in an attempt maximize the solar contribution into the energy matrix [1].

The following sections are dedicated to present the methods applied for determining the energy generation by using the System Advisor Model (SAM), a free software that allows technical analysis for all the technologies of interest, as well as for calculating the economic indicators. In the sequence, the results are presented and discussed.

\section{Methodology}

The main objective of this study is to evaluate the technical and economic feasibility of the implementation of four different CSP technologies in Brazil. A large scale photovoltaic power plant is also analyzed. For fair comparison, all the plants evaluated have equal capacity of $100 \mathrm{MWe}$. The System Advisor Model (SAM) software is employed in order to obtain the energy generation of each technology over the total lifetime of 30 years.

In order to assess each plant's economic viability, the methodology of this study is split into 5 consecutive stages, applied to each technology separately. They are presented in Table I.

On the first stage of the study, the project data employed to simulate the technical performance of each of the targeted technologies was obtained from the literature regarding solar plants around the globe [8]-[11]. Simulations were carried out to obtain a variety of outcomes, such as the total energy production over the plant's lifetime, the capacity factor, and the solar to electric efficiency conversion. The characteristics of the proposed solar plants are summarized in Table II.

Validation of the technical data was made by comparing the simulated plant's results to the outcomes presented by the respective reference, considering as acceptable a maximum mean absolute percentage error of 6\% [12] for energy generation, capacity factor and solar-to-electric efficiency (SEE). After the endorsement of the technical data, each plant was then simulated considering the meteorological data for one Brazilian city with high incidence of DNI. The city of Bom Jesus da Lapa (latitude

\begin{tabular}{cl}
\multicolumn{1}{c}{ Table I: Methodology } \\
\hline Stage & \multicolumn{1}{c}{ Definition } \\
\hline 1 & $\begin{array}{l}\text { Validation of the power plant's technical } \\
\text { data obtained from the literature. }\end{array}$ \\
\hline 2 & $\begin{array}{l}\text { Simulation of the validated plant's technical } \\
\text { parameters considering a Brazilian city. }\end{array}$ \\
\hline 3 & $\begin{array}{l}\text { Set up the cash flow model, which includes the } \\
\text { associated costs of the power plant, the } \\
\text { gross revenue obtained by selling the energy } \\
\text { on the Brazilian regulated environment, and the } \\
\text { taxations and incentives applied to the energy market. }\end{array}$ \\
& $\begin{array}{l}\text { Techno-economic assessment of the plant's } \\
\text { feasibility, considering four main economic } \\
\text { indicators, as well as the plant's energy output, } \\
\text { capacity factor and total land area. }\end{array}$ \\
\hline 5 & $\begin{array}{l}\text { Sensitivity analysis of the economic indicators } \\
\text { to the fluctuations of several economic parameters }\end{array}$ \\
\hline
\end{tabular}

Table II: Design characteristics of the simulated plants

\begin{tabular}{|c|c|c|}
\hline Solar Plants & Parameter & Value \\
\hline \multirow{4}{*}{ DS [8] } & Number of collectors & 4000 \\
\hline & Number of collectors North-South & 50 \\
\hline & Number of collectors East-West & 80 \\
\hline & Total solar field area $\left[\mathrm{m}^{2}\right]$ & 900000 \\
\hline \multirow{4}{*}{ ST [9] } & Number of heliostats & 7759 \\
\hline & Heliostat area $\left[\mathrm{m}^{2}\right]$ & 144.38 \\
\hline & Total land area [acres] & 1614 \\
\hline & Tower height $[m]$ & 177.99 \\
\hline \multirow{4}{*}{ PV [9] } & Parallel strings & 16817 \\
\hline & Modules per string & 18 \\
\hline & PV modules & 302706 \\
\hline & Number of inverters & 1389 \\
\hline \multirow{4}{*}{ PTC [10] } & Number of loops & 194 \\
\hline & Row spacing $[\mathrm{m}]$ & 15 \\
\hline & Single loop aperture $\left[\mathrm{m}^{2}\right]$ & 5248 \\
\hline & Total solar field area [acres] & 881 \\
\hline \multirow{3}{*}{ LFR [11] } & Number of loops & 140 \\
\hline & Single loop aperture $\left[\mathrm{m}^{2}\right]$ & 7524.80 \\
\hline & Number of modules per loop & 15 \\
\hline
\end{tabular}

$13^{\circ} 14^{\prime} \mathrm{S}$, longitude $43^{\circ} 24^{\prime} \mathrm{W}$, altitude $441.5 \mathrm{~m}$ ), located at the Brazilian semiarid region, was chosen for the case study. The weather data files applied in these simulations were obtained at the National Solar Radiation Database (NSRDB) [13]. The overall mean DNI and GHI of this region are, respectively, 5.75 $\mathrm{kWh} / \mathrm{m}^{2} /$ day and $6.23 \mathrm{kWh} / \mathrm{m}^{2} /$ day, while the average ambient temperature is $25.8^{\circ} \mathrm{C}$. The average wind speed through the year is about $1.5 \mathrm{~m} / \mathrm{s}$. These characteristics indicate that the region is a favorable site for the implementation of the CSP and PV projects.

Considering that the energy produced is sold at the Brazilian regulated market under a predefined price, the next stage of the methodology is the design of the cash flow of each project, with the purpose of measuring all cash inflows and outflows during each plant's lifetime. Table III contains the cash flow model developed for this study, taking into account that the sale of each plant's generated electricity occurs through contracts established at electricity auctions, which are carried out by the Chamber of Electric Energy Commercialization (CCEE).

Table III: Cash flow model

\begin{tabular}{cl}
\hline Cash Flow Model & \\
\hline$(+)$ & Gross Revenue \\
$(-)$ & Gross Revenue taxes \\
$(=)$ & Net Revenue \\
$(-)$ & Operational expenses \\
$(=)$ & Profit Before Income Tax (PBIT) \\
$(-)$ & Taxes \\
$(=)$ & Net profit (NP) \\
$(+)$ & Return of Investment Capital \\
$(-)$ & Investment \\
$(+)$ & Funding \\
$(-)$ & Funding amortization \\
$(=)$ & Free Cash Flow to Equity (FCFE)
\end{tabular}

Through the cash flow, the techno-economic assessment of the plants' feasibility on Brazil is evaluated. Four economic indicators are examined through this deterministic analysis: the Net Present Value (NPV), the Modified Internal Rate of Return 
(MIRR) and the Levelized Cost of Energy (LCOE) and the discounted Payback.

The NPV is defined as the difference between the present value of cash inflows and outflows over a period of time, and is given by (1).

$$
N P V=\sum_{n=0}^{t} \frac{C_{n}}{(1+i)^{n}}
$$

Where $C_{n}$ is the net cash flow on the year $n, i$ is the discount rate of the NPV and $t$ is the plant's lifetime.

The discount rate at which the NPV of the future cash flows is equal to the initial investment, being called the internal rate of return (IRR). However, projects that have alternating positive and negative cash flows have more than one IRR, which may generate ambiguity. The MIRR, given by (2), is a viable solution to this problem.

$$
M I R R=\left(\frac{\sum_{n=0}^{t} P C F_{n}\left(1+R_{r}\right)^{t-n}}{\sum_{n=0}^{t} \frac{\left|N C F_{n}\right|}{\left(1+R_{f}\right)^{n}}}\right)^{\frac{1}{t}}-1
$$

Where $P C F_{n}$ is the positive cash flow at year $n \mathrm{~m} R_{r}$ is the reinvestment rate applied to the $\mathrm{PCF}$ and $R_{f}$ is the finance rate applied to the negative cash flow $N C F_{n}$.

The LCOE measures the average net present cost of electricity generation for a power plant over its lifetime, as given by (3).

$$
L C O E=\frac{I_{0}+\sum_{n=1}^{t} \frac{A_{n}}{(1+i)^{n}}}{\sum_{n=1}^{t} \frac{E_{n}}{(1+i)^{n}}}
$$

In (3), $I_{0}$ is the initial investment, $A_{t}$ is the annual cost on the year $n$ and $E_{n}$ is the total energy produced by the system over the same year $n$.

Each economic indicator is responsible for one criteria utilized by investors to assess the feasibility of a project. The NPV of an investment, for example, must be positive in order to be deemed economically feasible. When analysing the MIRR, however, the economic viability is only achieved when the indicator is higher than the minimum acceptable rate of return (MARR).

Both the discounted Payback period and the LCOE are secondary indicators that are analysed after the performance evaluation for both MIRR and NPV. The Payback period can be comprehended as the amount of time that it takes for the initial cost of a project to match the discounted value of the cash flows over the plant's lifetime, and the LCOE is used mainly to compare the cost of generating electricity between the targeted technologies.

The last step of the methodology presented in Table I consisted of the identification of the technical or economic parameters that have the most impact on the presented indicators and, consequently, on the CSP power plant feasibility in Brazil. The sensitivity analysis considered as input values the unit cost of the plant's equipment, the energy purchase price under the regulated Brazilian market and the discount rate utilized.

Utilizing the data acquired by the sensitivity analysis, an optimistic analysis was designed, observing each plant's economic performance under more favorable conditions to investors. Through this process, it is possible to provide important data on the main parameters that must be observed by decision-makers of the regulation agencies in order to turn CSP projects into attractive solutions to investors.

\section{Results}

The simulations carried out by SAM employ a combination of an hourly simulation database with performance, costs and finance models to calculate the overall energy output and the energy costs of the solar plants.

The results for the economic assessment are presented in the following order: firstly, the results for the validation of the technical input parameters is shown. Subsequently, it is displayed the result of the simulations carried out for the Brazilian city of Bom Jesus da Lapa, labeled as the base case scenario. In this stage, it is also presented the techno-economic analysis for the base case. Lastly, the results achieved by the sensitivity analysis and the simulation of an optimistic scenario are shown.

\section{A. Validation of the technical parameters}

In order to evaluate the technical and economic performance of the CSP and PV simulation models under the Brazilian scenario, it is necessary to validate the technical parameters obtained from the literature. Each plant was simulated applying the weather data of it's respective reference. The values of electricity production, capacity factor, and SEE were extracted. The simulation outputs are then compared to the results achieved by the references [8]-[11], and the results of the percentage mean

\begin{tabular}{|c|c|c|c|}
\hline Solar Plant & Energy yield & Capacity Factor & SEE \\
\hline $\mathrm{ST}$ & $-5,68 \%$ & $-5,80 \%$ & $-2,55 \%$ \\
\hline PTC & $3,25 \%$ & $4,56 \%$ & $-0,42 \%$ \\
\hline LFR & $3,07 \%$ & $3,31 \%$ & $-4,37 \%$ \\
\hline DS & $-1,65 \%$ & $4,45 \%$ & $5,92 \%$ \\
\hline PV & $2,45 \%$ & $2,27 \%$ & $0,29 \%$ \\
\hline
\end{tabular}
error for the energy yeld, capacity factor, and SEE are shown in Table IV.

It is possible to verify that the error measured for each output does not overcome the established maximum threshold of $6 \%$ for any of the proposed technologies, which endorses the technical data acquired for the solar plants. The discrepancies might be explained by a slight incompatibility between the meteorological data used by the references and the simulations, as the technical outputs obtained by SAM are very sensitive to any divergence in the plant's technical attributes.

\section{B. CSP and PV plants technical performances}

The proposed base case evaluates the technical and economic performances of the solar plants on the Brazilian scenario.

Figure 1 presents the hourly DNI and GHI of the Bom Jesus da Lapa site through a typical year. It is noticeable the overall high levels of solar irradiation, specially on the months of February, September, October and December. This is mainly due to the weather characteristics of the Brazilian semiarid, which allows for clear sky availability during most of the typical year.

Table $\mathrm{V}$ presents the summary of the technical performance results obtained by SAM through the simulations. In terms of energy production and capacity factor, the ST plant has the best performance of all the studied technologies. However, it does require a considerable large area to generate energy, which may impact significantly the economic feasibility of this technology. It is also noted that even though the energy production of the 


\begin{tabular}{lccccc}
\hline & ST & PTC & LFR & DS & PV \\
\hline Energy produced at year 1 (GWh) & 372.66 & 333.39 & 305.74 & 185.20 & 231.88 \\
Capacity Factor (\%) & 42.50 & 37.80 & 34.90 & 21.10 & 26.50 \\
SEE (\%) & 16.30 & 16.56 & 18.23 & 27.48 & 17.84 \\
Electrical efficiency (\%) & 87.86 & 84.60 & 91.23 & 95.80 & X \\
Performance Ratio(\%) & X & x & X & X & 77.4 \\
Total land area (acres) & 1613.99 & 881.00 & 416.00 & 221.99 & 364.57 \\
\hline
\end{tabular}

Table VI: Economic input data

\begin{tabular}{ll}
\hline Parameter & Value \\
\hline Projects lifetime & 30 years \\
Minimum attractive rate of return & $7.16 \%$ a.a. (WACC) [14] \\
Reinvestment rate $\left(R_{r}\right)$ & Cost of equity \\
Finance rate $\left(R_{f}\right)$ & Cost of debt \\
Electricity transmission tariff & USD 0.375/kW.month \\
ANEEL inspection tax & $0.5 \%$ of the gross revenue \\
O\&M costs & USD 17.5/kW/year [15] \\
Linear depreciation & 30 years \\
Auction price & USD 74.93/MW [16] \\
Exchange rate & R\$ 4.00/USD (average 2019 price) \\
Average land cost & USD 625.48 [17] \\
\hline
\end{tabular}
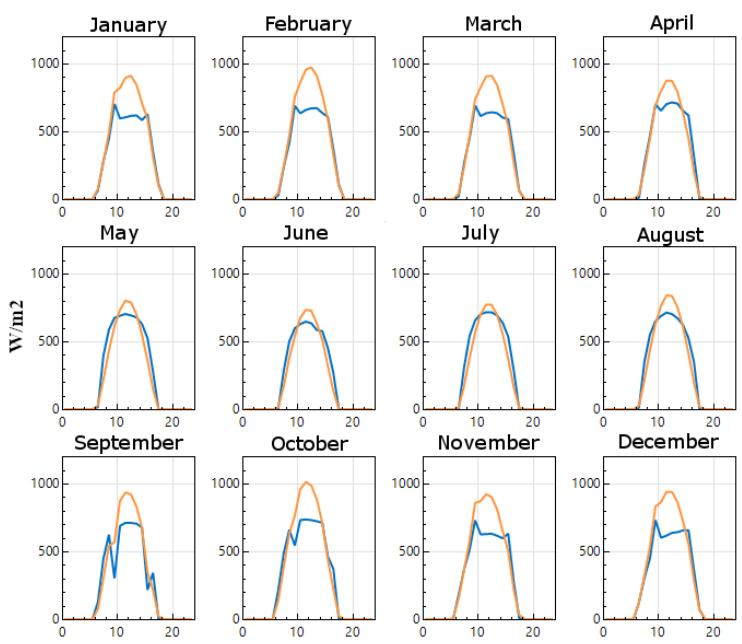

Figure 1: DNI and GHI for Bom Jesus da Lapa

PTC plant is about 9\% higher than the energy obtained from the LFR plant, the land area required by the former is almost two times higher than the latter.

Regarding the SEE, the DS plant has the highest conversion efficiency of all the technologies, mainly due to the tracking system employed, which allows for the constant tracking of the sun rays during the day. The lack of a storage system, however, debilitates the overall energy production and capacity factor. Finally, the PV plant has a satisfactory performance in terms of energy production, considering that it also lacks a storage system.

\section{Economic assessment}

After the evaluation of the technical performance of all the proposed solar plants, the outputs extracted from SAM are utilized as inputs to the economic model. The sale of electricity generated by the plant occurs through contracts resulting from electricity auctions carried out by the Chamber of Electric Energy Commercialization. To calculate the annual costs, both the direct (solar field, receiver, storage, turbines, heat transfer fluid) and the indirect costs (O\&M, land use, installation and transmission) are accounted, together with the taxes contemplated by the cash flow model.
To assess the economic viability of the proposed plants through the economic indicators, data regarding the cost of equity and debt was collected [18], as well as auction prices, taxation, and other assumptions. Tables VI and VII present data and assumptions necessary to the construction of the cash flow of the projects. The auction price was chosen to evaluate a favorable scenario to the implementation of energy sources with high production costs, simulating CSP market conditions similar to those observed during the initial stages of PV implementation on the Brazilian regulated environment. It is worth mentioning that the Weighed Average Capital Cost (WACC) was used as the minimum attractive rate of return for this study. The value of $7.16 \%$ is based on a historic series, and is calculated by ANEEL [14].

\begin{tabular}{l} 
Table VII: Input data used to calculate equity and debt rates [18] \\
\cline { 2 - 2 } \multicolumn{2}{c}{ Equity } \\
\cline { 2 - 2 } \begin{tabular}{ll} 
Risk Free rate & $4.59 \%$ \\
Market premium risk & $5.79 \%$ \\
Average unlevered beta & 0.44 \\
Country risk premium & $3.52 \%$ \\
Average USA inflation & $2.47 \%$ \\
Nominal equity & $10.65 \%$ \\
Real equity & $7.95 \%$ \\
\hline & \\
\hline \multicolumn{1}{c}{ Debt } \\
Credit risk premium & $2.93 \%$ \\
Nominal debt & $11.04 \%$ \\
Real debt & $8.34 \%$ \\
\hline
\end{tabular}
\end{tabular}

Table VIII presents the results obtained to all four indicators studied, and all of them point to the economic unfeasibility of the proposed CSP projects in the Brazilian scenario. The negative NPV indicates that the initial investment exceeds the present value of the revenue obtained through the CSP plants' lifetime. Both MIRR and Discounted Payback indicators also demonstrate unfeasibility. The MIRR is considerably inferior to the minimum attractive rate of return for all cases. On the other hand, the Discounted Payback infers that the CSP projects cannot be paid during their lifetime.

The only project to achieve economic feasibility is the PV plant, with positive values to the NPV, reduced LCOE and the highest MIRR value. Therefore, investment in large scale PV 
Table VIII: Economic indicators

\begin{tabular}{lccccc}
\hline & ST & PTC & LFR & DS & PV \\
\hline NPV (million USD) & -377.36 & -340.26 & -321.38 & -212.23 & 604.87 \\
MIRR (\%) & 4.52 & 4.55 & 4.43 & 4.06 & 9.65 \\
Payback (years) & $>30$ & $>30$ & $>30$ & $>30$ & 11.09 \\
LCOE (USD/kWh) & 0.150 & 0.152 & 0.155 & 0.163 & 0.041 \\
\hline
\end{tabular}

plants would be advised in this base case. This is expected, as PV projects have been present in Brazil since 2015, with many regulatory incentives, and fairly low production costs.

\section{Sensitivity analysis of the CSP plants}

Considering that the CSP plants are not yet competitive under the current market conditions compared to PV plants, it is crucial to understand what are the main causes behind the unsatisfactory performances of ST, PTC, LFR and DS technologies. An interesting approach to the problem is the development of a sensitivity analysis, evaluating what variables impact the most the cash flow and, therefore, the economic feasibility of the projects.

From the investor's point of view, the two most relevant economic parameters that may, roughly speaking, impact on the feasiblity of a project are the auction prices (which affect the gross revenue of a plant) and the costs of production (equipment, maintenance, installation).

Figures 2 and 3 present, respectively, the sensitivity of the NPV and MIRR to the variation of the energy selling price. On both figures, a red dashed line represents the point where the economic feasibility is reached. For Figure 2, this happens when NPV reaches 0 . The ST plant become viable for selling prices higher than USD $0.1711 / \mathrm{kWh}$, against USD $0.1739 / \mathrm{kWh}$ for the PTC plant, USD $0.1769 / \mathrm{kWh}$ for the LFR plant and USD $0.1855 / \mathrm{kWh}$ for the DS technology.

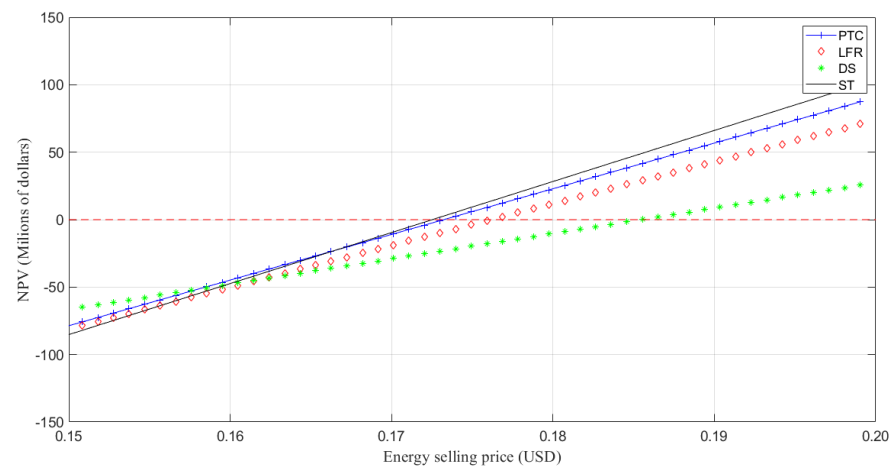

Figure 2: NPV sensitivity to the variation of the energy selling price

As shown in Figure 3, economic feasibility is only reached when the MIRR is higher than the minimum acceptable rate of return of $7.16 \%$. The maximum price required is USD $0.1528 / \mathrm{kWh}$, by the DS technology. In general, both results indicate that the energy price is a very important factor when considering the implementation of CSP technologies. Moreover, the results highlight that even though feasibility was attained, this was only possible for reasonably elevated prices, which are not competitive when compared to current market trends of wellestablished generation technologies.

Figure 4 shows the sensitivity of the NPV to variation on the installation costs of the CSP plants. The sensitivity parameter range was based on the Renewable Power Generation Costs

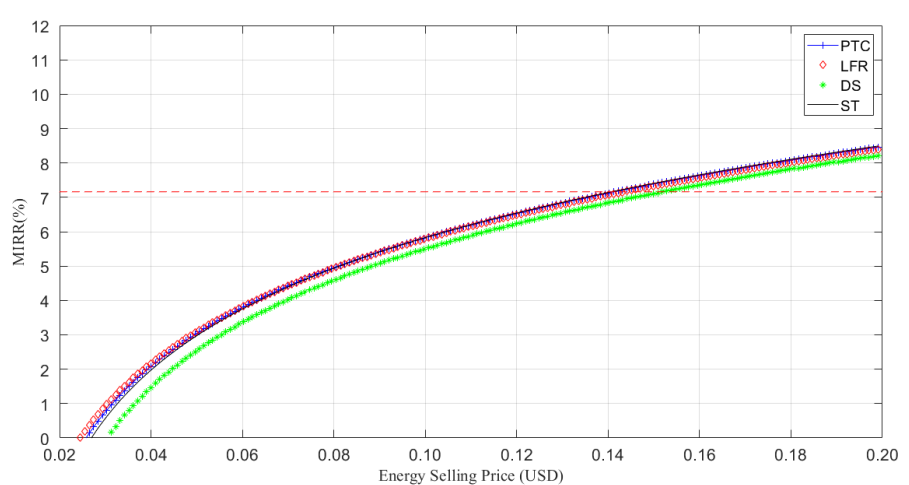

Figure 3: MIRR sensitivity to the variation of the energy selling price

report [19], published by the International Renewable Energy Agency (IRENA). For all technologies, feasibility couldn't be attained even with costs reductions of roughly $70 \%$. Nonetheless, it can still be concluded that the direct and indirect costs of the CSP plants have a significant impact on the feasibility, as a reduction of $68,2 \%$ on the overall instalation costs is associated with an NPV increase of more than $76 \%$ for the ST plant, against $70 \%$ for the PTC technology, $64 \%$ for the LFR plant and $56 \%$ for the DS system.

Other economic parameters were evaluated as well, such as the exchange rate and discount rate. Even though these variables have little impact on the financial viability when studied separately, they can greatly improve all economic indicators when combined with other parameters.

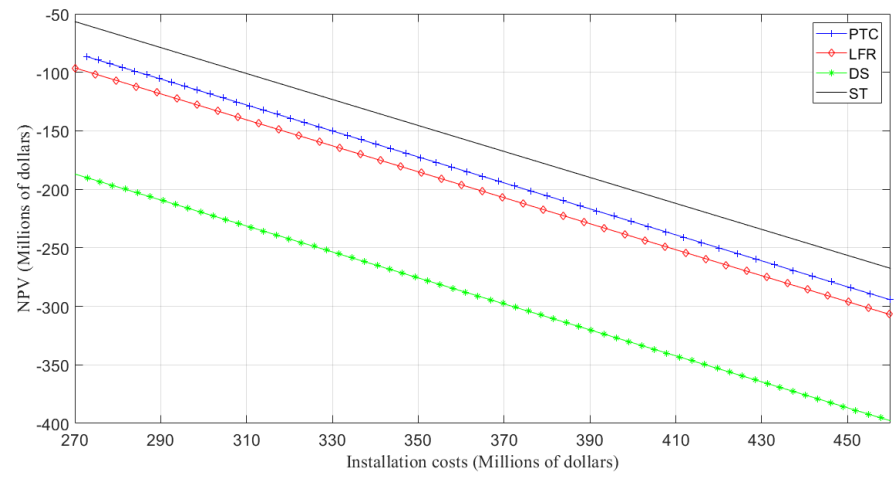

Figure 4: NPV sensitivity to the variation of the installation costs

\section{E. Optimistic case study}

With the information collected through the sensitivity analysis, an optimistic scenario was proposed, in which a new economic assessment was made considering various changes to key parameters that impact the feasibility of the CSP projects. This was made with the objective to evaluate the performance of each plant under a favorable environment that includes electricity generation incentives, competitive energy prices and cost reduction.

The proposed case assumes a 50\% reduction on the installation costs for all CSP technologies, based on historical cost reduction data for CSP equipment, measured by IRENA [19]. In terms of the renewable energy commercialization, an average price of USD 88,57 dollars $/ \mathrm{kWh}$ was chosen, established by ANEEL for PV energy in 2015, when the technology was being implemented. As an incentive, a reduction of $50 \%$ on the electricity transmission tariff was applied, based on the Normative Resolution 77/2004 by ANEEL [20]. Finally, a rate of 
Table IX: Economic indicators results for both the Optimistic and Base cases

\begin{tabular}{llcccc}
\hline & Scenario & NPV (USD) & MIRR (\%) & Payback (years) & LCOE (USD/kWh) \\
\hline \multirow{2}{*}{ ST } & Optimistic & 136.95 million & 8.75 & 13.43 & 0.0556 \\
& Base & -377.36 million & 4.52 & $>30$ & 0.1500 \\
\multirow{2}{*}{ PTC } & Optimistic & 114.95 million & 8.66 & 13.94 & 0.0573 \\
& Base & -340.26 million & 4.55 & $>30$ & 0.1525 \\
\multirow{2}{*}{ LFR } & Optimistic & 101.65 million & 8.58 & 14.40 & 0.0582 \\
& Base & -321.38 million & 4.43 & $>30$ & 0.1549 \\
& & & & & \\
DS & Optimistic & 53.06 million & 8.53 & 14.66 & 0.0594 \\
& Base & -212.23 million & 4.06 & $>30$ & 0.1625 \\
\hline
\end{tabular}

return of 5\% was considered, based on the Special Custodial and Clearing System (in Portuguese, Sistema Especial de Liquidação e de Custódia - SELIC) managed by Brazilian Central Bank (BACEN).

Table IX presents the results of both the optimistic scenario and the base case. It can be observed that all the economic indicators showed considerable improvement under favorable conditions. All indicators show that the ST technologies has the best performance of all CSP plants simulated in Brazil. Both PTC and LFR technologies have similar performance, but the former has higher financial attractiveness due to better technical performance.

\section{CONCLUSION}

This study provides several inputs for the decision-making process regarding the implementation of solar thermal systems on Brazil, and the incentives needed in order to make it an attractive solution to investors on renewable energy.

The energy results obtained by the simulations carried out by SAM show a promising future for the concentrating solar technology in the Brazilian market. The ST technology, of all the CSP plants, has the best performance in terms of energy production, capacity factor and electrical efficiency.

It is evident, through the results achieved by this study, that the four main CSP technologies are not competitive nor profitable at Brazilian territory. A sensitivity analysis was carried out, outlining that the implementation of CSP plants still need incentives in order to overcome barriers like the high installation costs. As international reports point out [19], there has been a significant decline on the CSP generation costs over the last decade, and more cost reduction is expected as technology improves.

One of the main obstacles that CSP technology faces is the equipment import dependence, which is subject to price fluctuations of the underlying commodities inputs, such as plastic, steel and concrete. A solution to this problem might be increasing the degree of supply of the commodities. The favorable performance of all CSP technologies observed on the optimistic scenario is a valuable tool that can enrich the decision-making process about incentive politics that affect the implementation of solar thermal systems on Brazil.

\section{REFERENCES}

[1] G. S. Torres, T. A. De Oliveira, A. Ferreira Filho, and E. G. Domingues, "Economical assess of concentrated solar tower power plants in the brazilian scenario," in VIII Simpósio Brasileiro de Sistemas Elétricos (SBSE), Aug 2020, pp. 1-6.

[2] T. A. De Oliveira, A. Ferreira Filho, and E. G. Domingues, "Technical analysis of a real and optimized concentrated solar power plant in the brazilian scenario," in 2019 Workshop on Communication Networks and Power Systems (WCNPS), Oct 2019, pp. 1-5.
[3] M. T. Islam, N. Huda, A. Abdullah, and R. Saidur, "A comprehensive review of state-of-the-art concentrating solar power (csp) technologies: Current status and research trends," Renewable and Sustainable Energy Reviews, vol. 91, pp. 987-1018, 2018.

[4] C. Amadei, G. Allesina, P. Tartarini, and W. Yuting, "Simulation of gemasolar-based solar tower plants for the chinese energy market: influence of plant downsizing and location change," Renewable energy, vol. 55, pp. 366-373, 2013.

[5] R. N. N. ANEEL, “482,” Estabelece as condições gerais para o acesso de microgeração e minigeração distribuída aos sistemas de distribuição de energia elétrica, o sistema de compensação de energia elétrica, e dá outras providências, vol. 17, 2012.

[6] X. Ju, C. Xu, Y. Hu, X. Han, G. Wei, and X. Du, "A review on the development of photovoltaic/concentrated solar power (pv-csp) hybrid systems," Solar Energy Materials and Solar Cells, vol. 161, pp. 305-327, 2017.

[7] I. Purohit and P. Purohit, "Technical and economic potential of concentrating solar thermal power generation in india," Renewable and Sustainable Energy Reviews, vol. 78, pp. 648-667, 2017.

[8] M. Abbas and N. K. Merzouk, "Techno economic study of solar thermal power plants for centralized electricity generation in algeria," in Environment Friendly Energies and Applications (EFEA), 2012 2nd International Symposium on. IEEE, 2012, pp. 179-183.

[9] A.-B. Awan, "Design, optimization and performance comparison of solar tower and photovoltaic power plants," Energy, vol. 199, 2020

[10] R. Praveen and M. A. Baseer, "Design, performance analysis and optimization of a $100 \mathrm{mw}$ concentrated solar power plant with thermal energy storage," in IEEE International Conference on Current Trends toward Converging Technologies, Coimbatore, India, 2018.

[11] D. Bishoyi and K. Sudhakar, "Modeling and performance simulation of $100 \mathrm{mw}$ lfr based solar thermal power plant in udaipur india," ResourceEfficient technologies, vol. 3, pp. 365-377, 2017.

[12] DOE, "Concentrating solar power commercial application study: reducing water consumption of concentrating solar power electricity generation," DOE, Tech. Rep., 2001

[13] NREL, "Solar resource data," NREL, Available on https://sam.nrel.gov/weather-data, Tech. Rep., 2021.

[14] ANEEL, "Nota técnica n89/2014-sre/aneel," ANEEL, Tech. Rep., 2014

[15] MME, "Nota técnica pr 07/18: Premissas e custos da oferta de energia elétrica no horizonte 2050," MME, Tech. Rep., 2018

[16] ANEEL, "Resultado dos leilões de geração no ambiente regulado," ANEEL, Disponível em https://www.aneel.gov.br/resultados-de-leiloes, Tech. Rep., 2020.

[17] INCRA, "Planilha de preços referenciais de terra (ppr)," INCRA, Disponível em http://antigo.incra.gov.br/pt/ramt-sr05-ba, Tech. Rep., 2018.

[18] T. P. Oliveira, "Metodologia para análise de risco de investimento em fontes de geração heliotérmica do tipo torre solar no mercado regulado brasileiro," Master's thesis, Universidade de Brasília, Programa de Pós Graduação em Engenharia Elétrica, 2020.

[19] IRENA, "Renewable power generation costs in 2019," IRENA, Tech. Rep., 2020.

[20] ANEEL, "Estabelece os procedimentos vinculados à redução das tarifas de uso dos sistemas elétricos de transmissão e de distribuição, para empreendimentos hidrelétricos e aqueles com base em fonte solar, eólica, biomassa ou cogeração qualificada." REN N 77, 2004, accessed in 08-012021. 